\title{
An Alternate Pathway for Visual Signal Integration into the Hypothalamo-Pituitary Axis: Retinorecipient Intergeniculate Neurons Project to Various Regions of the Hypothalamus and Innervate Neuroendocrine Cells Including Those Producing Dopamine
}

\author{
Tamas L. Horvath \\ Department of Obstetrics and Gynecology, Yale University School of Medicine, New Haven, Connecticut 06520
}

Using tract tracing and immunocytochemistry, this study explored the connectivity between lateral geniculate efferents and neurons of the hypothalamus, including those producing dopamine, that have direct access to fenestrated capillaries. It was also determined whether the intergeniculate neurons that give rise to hypothalamic projections are targeted by retinal axons.

Within the hypothalamus, Phaseolus vulgaris leucoagglutininlabeled, lateral geniculate efferents were observed in the suprachiasmatic nucleus, subparaventricular area, periventricular nuclei, medial preoptic areas, and between the arcuate and ventromedial nuclei. In these sites, intergeniculate efferents contacted populations of neurons that were retrogradely labeled from fenestrated capillaries by the intraperitoneal injection of fluorogold. Hypothalamic dopamine neurons, a population of which was neuroendocrine, were also synaptic targets of lateral geniculate efferents. After injection of the retrograde tracer fluorogold into these hypothalamic projection sites in parallel with bilateral enu- cleation, retrogradely labeled perikarya were restricted to the intergeniculate leaflet. All of the labeled perikarya contained infolded nuclei, and their distal dendrites were frequently found to be contacted by degenerated, retinal fibers.

This study provides morphological evidence for a signaling pathway from the retina through the intergeniculate leaflet to hypothalamic cells that participate in neuroendocrine regulations. These observations raise the possibility that visual signals independent of the circadian clock may also influence the hypothalamo-pituitary axis. In light of the overlapping distribution of intergeniculate and suprachiasmatic efferents in the hypothalamus and their similar relationship with neuroendocrine cells, it is suggested that integration of circadian and visual signals can occur outside of the suprachiasmatic nucleus to regulate endocrine rhythms.

Key words: retina; intergeniculate leaflet; hypothalamus; neuroendocrine cells; dopamine; anterior pituitary
The circadian timing system of mammals supports different functions in reproduction. The appropriate alternation of light/dark cycles and the interaction among the visual, circadian, and neuroendocrine systems are essential in the maintenance of rhythmic secretion of prolactin and luteinizing hormone ( $\mathrm{LH}$ ) (Antunes et al., 1967; Brown-Grant and Raisman, 1977; Kawakami et al., 1980; Pan and Gala, 1985). For example, exposure to constant light induces the emergence of impaired LH and prolactin secretions, leading to the failure of ovarian cycles (Critchlow, 1963; Brown-Grant et al., 1973; Pieper and Gala, 1979; Vaticon et al., 1980; Sartin et al., 1981; Watts and Fink; 1981a,b; Nir and Hirschmann, 1982; Sterner and Cohen 1995).

It was postulated that a tightly coupled relationship exists between the retino-recipient suprachiasmatic nucleus (SCN) and the principal regulatory cells in gonadotropin and prolactin secretion, the luteinizing hormone-releasing hormone (LHRH)and dopamine-producing neurons, because: (1) there is a lack of SCN efferents in the median eminence, the site where neurohormones are released into the portal capillaries and are transported

Received Sept. 19, 1997; revised Nov. 26, 1997; accepted Dec. 4, 1997

This work was supported by National Institutes of Health Grant NS-36111. Part of this study was presented at the 26th Annual Meeting of the Society for Neuroscience, Washington DC, 1996, abstract 65.6.

Correspondence should be addressed to Dr. Tamas L. Horvath, Yale Medical School, Department of Obstetrics and Gynecology, 333 Cedar Street, FMB 339, New Haven, CT 06520.

Copyright (C) 1998 Society for Neuroscience $\quad 0270-6474 / 98 / 181546-13 \$ 05.00 / 0$ to the anterior pituitary; and (2) the LHRH and dopamine cells are located in areas of the hypothalamus that are targeted by SCN efferents (Chan-Palay et al., 1984; van den Pol et al., 1984; Watts and Swanson, 1987; Watts et al., 1987; Kawano and Daikoku, 1987). Recent evidence confirmed this suggestion by demonstrating synaptic interactions between SCN efferents and LHRHproducing (van der Beek et al., 1997) and dopamine-producing hypothalamic perikarya (Horvath, 1997). These observations provided a signaling pathway for circadian regulation of the hypothalamo-pituitary axis. However, the constant light-induced malfunctioning of the anterior pituitary cannot be easily understood by this signaling modality; during constant light, the circadian pacemaker free runs (Honma and Hiroshige, 1978). However, the circadian daily and preovulatory gonadotropin and prolactin secretions are abolished (Critchlow, 1963; Brown-Grant et al., 1973; Sartin et al., 1981; Watts and Fink, 1981a,b). Although arrhythmicity in SCN activity was also detected in animals kept in constant light, which could cause impaired hormone secretions (Morimoto et al., 1975), it may be that during exposure to constant light, photic stimuli can continuously reach neuroendocrine cells via a pathway that does not involve the SCN.

A brain region that has the potential to mediate noncircadian visual information to the hypothalamus is the intergeniculate leaflet (IGL) of the lateral geniculate nucleus (LGN); it receives direct visual input (Hickey and Spear, 1976) and has not been shown to have intrinsic circadian activity, and cells of the IGL 
innervate extrasuprachiasmatic areas of the hypothalamus (Mikkelsen, 1990a,b; Moore et al., 1996). The present study explored the interconnection between LGN efferents and neurons of the hypothalamus, including those producing dopamine that are neuroendocrine; i.e., they have direct access to fenestrated capillaries. These cells can release their products to the portal vessels in the median eminence that provides the humoral link between the hypothalamus and the anterior pituitary. This study also aimed to determine whether intergeniculate neurons that give rise to hypothalamic projections are direct targets of retinal axons.

\section{MATERIALS AND METHODS}

\section{Animals}

Female Sprague Dawley rats (250-280 gm body weight) were kept under standard laboratory conditions: tap water and standard rat chow ad libitum and $12 \mathrm{hr}$ light/dark cycle. Two sets of experiments were performed on two groups of randomly selected females (the status of the estrous cycle was not determined). One group included animals $(n=6)$ in which LGN efferents were labeled with Phaseolus vulgaris leucoagglutinin (PHA-L) and neuroendocrine cells with systemic fluorogold (FG) injections. In another group of rats $(n=6)$, retrograde labeling of LGN neurons was performed on enucleated animals by iontophoretic injections of FG into extrasuprachiasmatic regions of the hypothalamus. All of the experimental procedures were approved by the Yale Animal Care Committee.

\section{PHA-L injections}

The projection field of LGN neurons was visualized by using PHA-L [2.5\% in $10 \mathrm{~mm}$ phosphate buffer (PB), $\mathrm{pH}$ 7.8; Vector Laboratories, Burlingame, CA] as an anterograde tracer. This was unilaterally applied by iontophoresis, via a glass micropipette (tip diameter, $15 \mu \mathrm{m} ; 5 \mu \mathrm{A}$ positive current applied every other $5 \mathrm{sec}$ for $15 \mathrm{~min}$ using a constant current source that is capable of generating up to $2000 \mathrm{~V}$; CS-3 Transcientics System, Canton, MA) into different areas of the IGL [coordinates: anteroposterior (AP), $-4.2 \mathrm{~mm}$; lateral (L), $3.6 \mathrm{~mm}$; ventral (V), $5.3 \mathrm{~mm}$, according to Paxinos and Watson, 1986].

\section{Fluorogold (FG) injection}

Simultaneously with the PHA-L injections, animals received a single intraperitoneal injection of FG $(20 \mathrm{mg} / \mathrm{kg}$ body weight in saline; Fluorochrome, Inc., Englewood, $\mathrm{CO}$ ) to label neurons that send projections to regions in the CNS that lack blood-brain barrier (Merchenthaler, 1991).

In a group of animals that were binocularly enucleated (see below), FG (2\% FG in saline) was applied into extrasuprachiasmatic sites where LGN efferents contacted neuroendocrine cells (AP, 0.0-1.3 mm; L, 0.2 $\mathrm{mm}$; V, 9.4-8.8 mm, according to Paxinos and Watson, 1986). These FG injections were applied iontophoretically, using the same parameters as for the PHA-L experiments (see above).

\section{Bilateral enucleation}

In a group of animals, in parallel with the FG injections, both eyes of the animals were surgically removed under ketamine anesthesia.

\section{Fixation and tissue preparation}

Fifteen days after PHA-L and FG injections and $5 \mathrm{~d}$ after FG and enucleation, rats were killed under metofane anesthesia by transaortic perfusion with $50 \mathrm{ml}$ of heparinized saline followed by $250 \mathrm{ml}$ of fixative. The fixative consisted of $4 \%$ paraformaldehyde, $15 \%$ picric acid, and $0.2 \%$ glutaraldehyde in $0.1 \mathrm{M} \mathrm{PB}, \mathrm{pH}$ 7.4. The brains were dissected out, and 3 -mm-thick coronal blocks containing the diencephalon were postfixed for an additional $1-2 \mathrm{hr}$ in glutaraldehyde-free fixative. Tissue blocks were rinsed in several changes of $\mathrm{PB}$, and $50 \mathrm{~mm}$ vibratome (Lancer) sections were prepared and rinsed four times for $15 \mathrm{~min}$ each in PB. Subsequently, sections for both light and electron microscopy were treated with $1 \%$ sodium borohydride in $\mathrm{PB}$ for $10 \mathrm{~min}$ to eliminate unbound aldehydes from the tissue.

\section{Immunostaining}

PHA-L and FG studies. Immunostaining for PHA-L, FG, and tyrosine hydroxylase $(\mathrm{TH})$ was performed according to a recently published protocol (Horvath, 1997). First, sections were incubated in biotinylated rabbit anti-PHA-L, 1:250 in PB containing 1\% normal goat serum and $0.3 \%$ Triton X-100 for $48 \mathrm{hr}$ at $4^{\circ} \mathrm{C}$. After several washes in PB, sections were incubated in avidin-biotin-peroxidase, 1:500 in PB (ABC kit, Vector), followed by a modified version of the Ni-DAB reaction $(15 \mathrm{mg}$ of DAB, $0.12 \mathrm{mg}$ of glucose oxidase, $12 \mathrm{mg}$ of ammonium chloride, 600 $\mathrm{ml}$ of $0.05 \mathrm{M}$ nickel ammonium sulfate, and $600 \mathrm{ml}$ of $10 \% \beta$-D-glucose in $30 \mathrm{ml}$ of $\mathrm{PB}$; dark blue reaction product) to visualize the tissue-bound peroxidase. Then, sections were further immunostained for FG. In this procedure, after a $48 \mathrm{hr}\left(\right.$ at $\left.4^{\circ} \mathrm{C}\right)$ incubation in rabbit anti-FG antiserum (Biogenesis, Inc., Franklin, MA) (1:5000 in PB containing 0.1\% sodium azide and $1 \%$ normal goat serum), sections were further processed in the secondary antibody (biotinylated goat anti-rabbit IgG, 1:250 in PB; Vector) for $2 \mathrm{hr}$ at room temperature and then rinsed in $\mathrm{PB}$ three times for $10 \mathrm{~min}$ each, and incubated for $2 \mathrm{hr}$ at room temperature with $\mathrm{ABC}$ Elite (Vector), 1:250 in PB, followed by the above-described Ni-DAB reaction. After several rinses in PB, every other section was placed on gelatincoated slides, dehydrated through increasing ethanol concentrations, and mounted with Permount. The remaining sections were further immunostained for $\mathrm{TH}$. In this procedure, after a $48 \mathrm{hr}\left(\right.$ at $\left.4^{\circ} \mathrm{C}\right)$ incubation in mouse anti-TH antiserum (Chemicon, Temecula, CA; 1:1000 in PB containing $0.1 \%$ sodium azide and $1 \%$ normal horse serum), sections were incubated in the secondary antibody (goat anti-mouse IgG), 1:50 in $\mathrm{PB}$ for $2 \mathrm{hr}$ at room temperature, followed by peroxidase-antiperoxidase (PAP), rabbit PAP, 1:100 in PB. Between each incubation step, sections were rinsed three times for $15 \mathrm{~min}$ each in PB. In this case, the tissue-bound peroxidase was visualized by a light brown DAB reaction (15 mg of DAB, $165 \mu \mathrm{l}$ of $0.3 \% \mathrm{H}_{2} \mathrm{O}_{2}$ in $30 \mathrm{ml}$ of PB, 5-10 min at room temperature; brown reaction product). After immunostaining of the third tissue antigen, sections were thoroughly rinsed in PB, placed on gelatin-coated slides, dehydrated through increasing ethanol concentrations, and mounted with Permount. In control experiments, one or two primary antibodies were replaced with normal serum resulting in only single or double immunolabeling.

For electron microscopic analysis, sections were processed the same way as for light microscopy, except the labeling of $\mathrm{TH}$ was performed before PHA-L and FG immunostaining using $5 \mathrm{~nm}$ immunogoldconjugated goat anti-mouse IgG (Polysciences, Warrington, PA) as secondary antiserum. Subsequently, sections were post-osmicated $\left(1 \% \mathrm{OsO}_{4}\right.$ in $\mathrm{PB}$ ) for $30 \mathrm{~min}$, dehydrated through increasing ethanol concentrations (using $1 \%$ uranyl acetate in the $70 \%$ ethanol, $30 \mathrm{~min}$ ) and flat-embedded in Araldite between liquid release (Electron Microscopy Sciences, Fort Washington, PA) coated slides and coverslips, and placed in an oven to polymerize for $48 \mathrm{hr}$ at $60^{\circ} \mathrm{C}$. Flat-embedded sections were fixed with a drop of embedding medium on the top of cylindrical araldite blocks and cured again for $48 \mathrm{hr}$ at $60^{\circ} \mathrm{C}$. Then, blocks were trimmed using light micrographs as a guide in recognizing the selected retrogradely labeled cells and contacts. Ribbons of ultrathin sections (Reichert-Jung Ultramicrotome) were collected on Formvar-coated single-slot grids and examined using a Philips CM-10 electron microscope.

FG and enucleation studies. In this case, only single labeling for FG was performed as described above using the polyclonal antiserum against FG and an $\mathrm{ABC}$ procedure followed by a DAB reaction (see above).

\section{RESULTS}

\section{PHA-L, FG, and TH labeling}

\section{$P H A-L$ injection and immunolabeling}

Six animals received PHA-L injections. Three of these injections were placed predominantly in the IGL as revealed by immunolabeling for PHA-L. Only tissues from these latter animals were fully processed according to the protocol.

Labeled perikarya were most abundant in the IGL, whereas PHA-L-immunoreactive cells were also found in the adjacent areas of both the ventral LGN (vLGN) and dorsal LGN (dLGN) (Fig. $1 A, B$ ). Labeled axons and axon terminals were detected in all parts of the LGN. In accordance with the labeled cell bodies, LGN efferents were observed in all previously reported projection sites of these nuclei, including the superior colliculus, posterior commissure, and contralateral LGN. This study focused on the hypothalamic projection sites.

Sections taken from the diencephalon and adjacent forebrain 

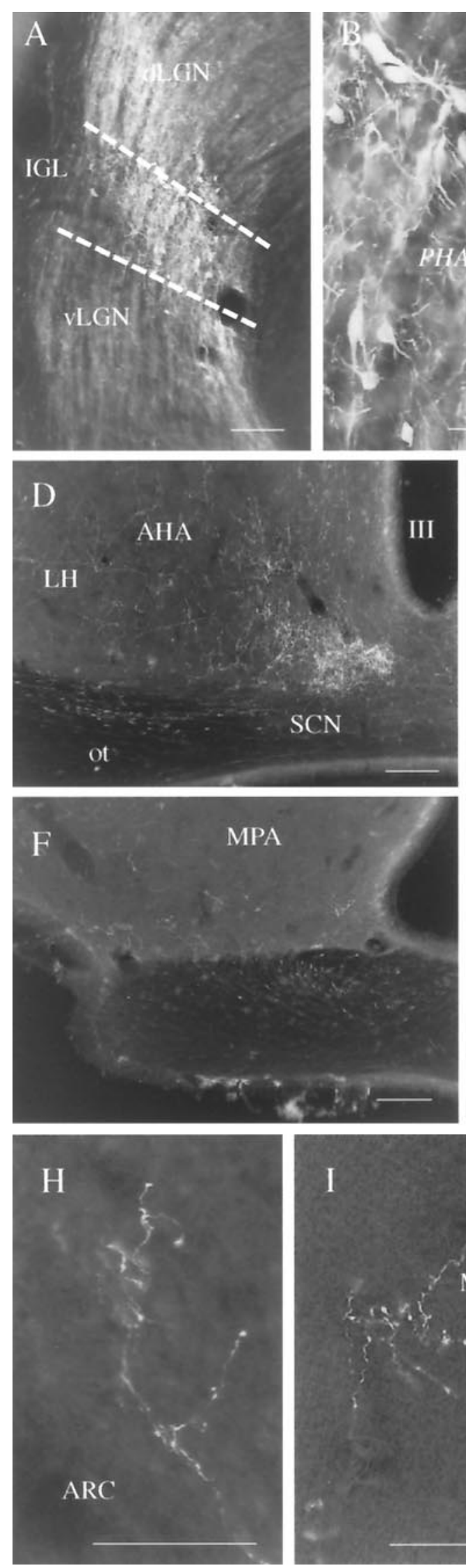
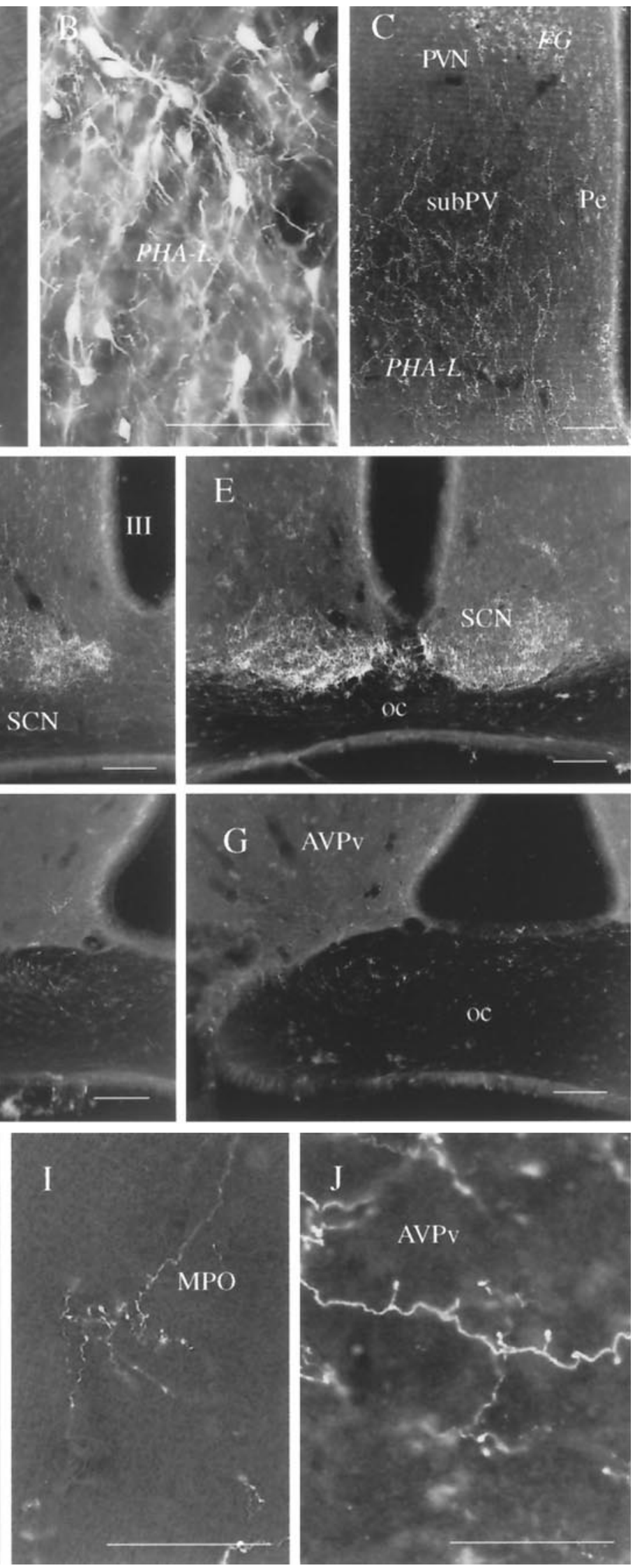

Figure 1. Anterograde labeling of LGN efferents by PHA-L. $A, B$, Typical injection site of the anterograde tracer PHA-L in the LGN. Although PHA-Limmunoreactive cells are present in al regions of the LGN, including the of labeled cells are located in the IGL. $B$, High-power magnification of the IGL area indicated on $A . C-G$, Anterogradely labeled LGN efferents in the subparaventricular region ( $\operatorname{subPV;C}$ ), lateral hypothalamus $(L H)$, periventricular area $(P e)$, and posterior SCN $(D)$, anterior SCN $(E) \mathrm{MPO}(F)$, and the anteroventral periventricular nucleus $(A V P v ; G)$. Labeled processes are also visible in the optic tract $(D)$ and chiasm $(E-G)$. On the other hand, the magnocellular region of the paraventricular nucleus $(P V N$ on $C)$ that contained a high number of FG-labeled cells after peripheral injection of the retrograde tracer does not seem to receive IGL efferents. $H-J$, High-power light micrographs showing axon arborizations and axon terminals in the posterior arcuate nucleus $(A R C ; H)$, MPO $(I)$ and the AVPv $(J)$. Scale bars: $A-C, H-J, 100 \mu \mathrm{m} ; D-G, 300 \mu \mathrm{m}$. 
areas showed that anterogradely labeled axons and axon terminals reached ventral aspects of the lateral and medial septal nuclei, diagonal band of Broca, bed nucleus of the stria terminalis, medial preoptic area (MPO), anteroventral periventricular nucleus (AVPv), medial preoptic nucleus periventricular region, parvocellular region of the paraventricular nucleus, subparaventricular zone, retrochiasmatic area, anterior hypothalamic nucleus, supraoptic decussation, suprachiasmatic nucleus, dorsomedial nucleus, ventrolateral aspects of the ventromedial nucleus, and the cell-sparse zone between the arcuate and ventromedial nuclei (Figs. $1 C-H, 2$ ). LGN efferents could also be detected in the ipsilateral optic tract and in both the ipsilateral and contralateral optic nerve (Fig. 1 $A, D$ ). The most abundant network of labeled fibers could be seen in the ventral aspects of the SCN and the subparaventricular zone. No labeled processes could be detected in the median eminence and organum vasculosum laminae terminalis, and only trespassing axons were found within the core of the arcuate nucleus and the magnocellular region of the paraventricular nucleus. Although most of the labeling was observed in the ipsilateral side, some axons were detected in contralateral areas as well. Contralateral innervation was the most pronounced in the SCN and the subparaventricular area. In the case of the $\mathrm{SCN}$, collaterals from the same axon could frequently be followed to both the ipsilateral and contralateral SCN.

In an attempt to compare the distribution pattern of SCN and IGL efferents in the hypothalamus, we analyzed serial vibratome sections immunostained for PHA-L from animals that received the tracer in the IGL (present studies) and the SCN (a previous experiment; see Horvath, 1997). On superimposing camera lucida drawings from the two experiments, it could be seen that the projection field of IGL efferents within the hypothalamus almost completely overlapped that of the SCN (Fig. 2). Also note that although a quantitative analysis could not be performed, the extent of the IGL innervation of different hypothalamic nuclei seemed to be comparable to that of the SCN.

\section{FG immunolabeling}

FG-immunopositive cell bodies and dendrites could be seen throughout the hypothalamus. Retrogradely labeled cells were abundant in the medial septum, medial preoptic area, organum vasculosum of laminae terminalis, diagonal band of Broca, supraoptic and paraventricular nuclei, arcuate nucleus, the area between the arcuate nucleus and ventrolateral parts of the ventromedial nucleus, and the zona incerta. Fewer cells could be seen in the periventricular area, including the subparaventricular zone and retrochiasmatic area, and in the lateral hypothalamus. No labeled neurons were detected in the SCN or IGL. The distribution of retrogradely labeled hypothalamic cells corresponded to earlier descriptions (Merchenthaler, 1991; Horvath, 1997). In accordance with previous studies (Morin and Blanchard, 1993), the intraperitoneal administration of FG resulted in a different appearance of the immunoperoxidase reaction product in cells than resulted from the iontophoretic application (see below). FG labeling in the former had a granular appearance, whereas, in the latter, FG labeling was homogeneously distributed in the IGL cells. It is likely that this difference is the result of the low levels of FG in the circulation, in contrast to the concentration given for iontophoretic application.

\section{TH immunostaining}

Immunolabeling for $\mathrm{TH}$ resulted in extensive staining throughout the hypothalamus. Labeled cell bodies and dendrites were found in the AVPv, MPO, periventricular area, parvocellular division of the paraventricular nucleus, anterior hypothalamus, arcuate nucleus, and zona incerta. Axonal processes were abundant in most of the hypothalamic nuclei. The median eminence contained an abundant network of TH-immunoreactive axonal processes in both its internal and external divisions. The appearance of TH-containing profiles in this experiment was in accordance with previous reports (Chan-Palay et al., 1984; van den Pol et al., 1984; Horvath et al., 1992a,b).

\section{FG-TH double labeling}

The granular appearance of FG immunoreactivity permitted the detection of the labeling of cytoplasmic TH. In all of the hypothalamic areas where TH immunoreactivity was detected, retrogradely transported FG was detected in a subpopulation of $\mathrm{TH}$ immunoreactive, putative dopamine neurons (Figs. 3, 4E-G2). The highest incidence of double-labeled cells was found in the arcuate nucleus (A12 dopaminergic cell group) followed by the periventricular area and the preoptic area (A14 dopaminergic cell group). In the zona incerta, no retrogradely labeled dopamine cells were detected, whereas numerous neurons nearby contained FG. The extent of colocalization of FG and $\mathrm{TH}$ in this study corresponds to earlier descriptions of neuroendocrine dopaminergic cells of the hypothalamus (Jonsson et al., 1971; van den Pol et al., 1984; Kawano and Daikoku,1987; Horvath, 1997).

\section{PHA-L-FG double labeling}

PHA-L-immunoreactive dark blue fibers were detected in several regions that contained retrogradely labeled FG-immunopositive neurons (Fig. 2). These regions included the medial septum, MPO, periventricular areas, subparaventricular zone, and a region between the arcuate and ventromedial nuclei (Fig. 3). In these regions, PHA-L-labeled LGN efferents could often be found in close proximity to distinct populations of FG-labeled cell bodies and proximal dendrites (Fig. $4 A, B$ ). Similar to the experience with SCN efferents (Horvath, 1997), the frequency of these connections was highest in periventricular areas, including the anteroventral periventricular nucleus, and in the cell-sparse zone between the arcuate and ventromedial nuclei. Fewer connections were found in the parvocellular division of the paraventricular nucleus. The putative connections were observed predominantly in the side ipsilateral to the injection, although a few connections were seen on the contralateral side as well.

\section{PHA-L-TH double labeling}

PHA-L-immunoreactive fibers were seen in close apposition to TH-immunolabeled cells within the MPO, AVPv, periventricular and retrochiasmatic regions, dorsomedial nucleus, and an area between the arcuate nucleus and the ventromedial nucleus (Figs. $2,3,4 C, D)$. The IGL target catecholaminergic cells were homogeneously distributed in the AVPv. In the periventricular region, most of these cells were located in ventral areas, whereas in the subparaventricular zone most of these cells were concentrated in the bordering regions of the parvocellular paraventricular nucleus, dorsomedial nucleus, and anterior hypothalamus. The majority of the appositions were between PHA-L-containing axons and the proximal dendrites of $\mathrm{TH}$ cells. However, axosomatic connections could also be detected.

\section{Triple-labeled cells}

In the hypothalamic regions (see above) where dopamine cells were detected to be retrogradely labeled, but most extensively in 


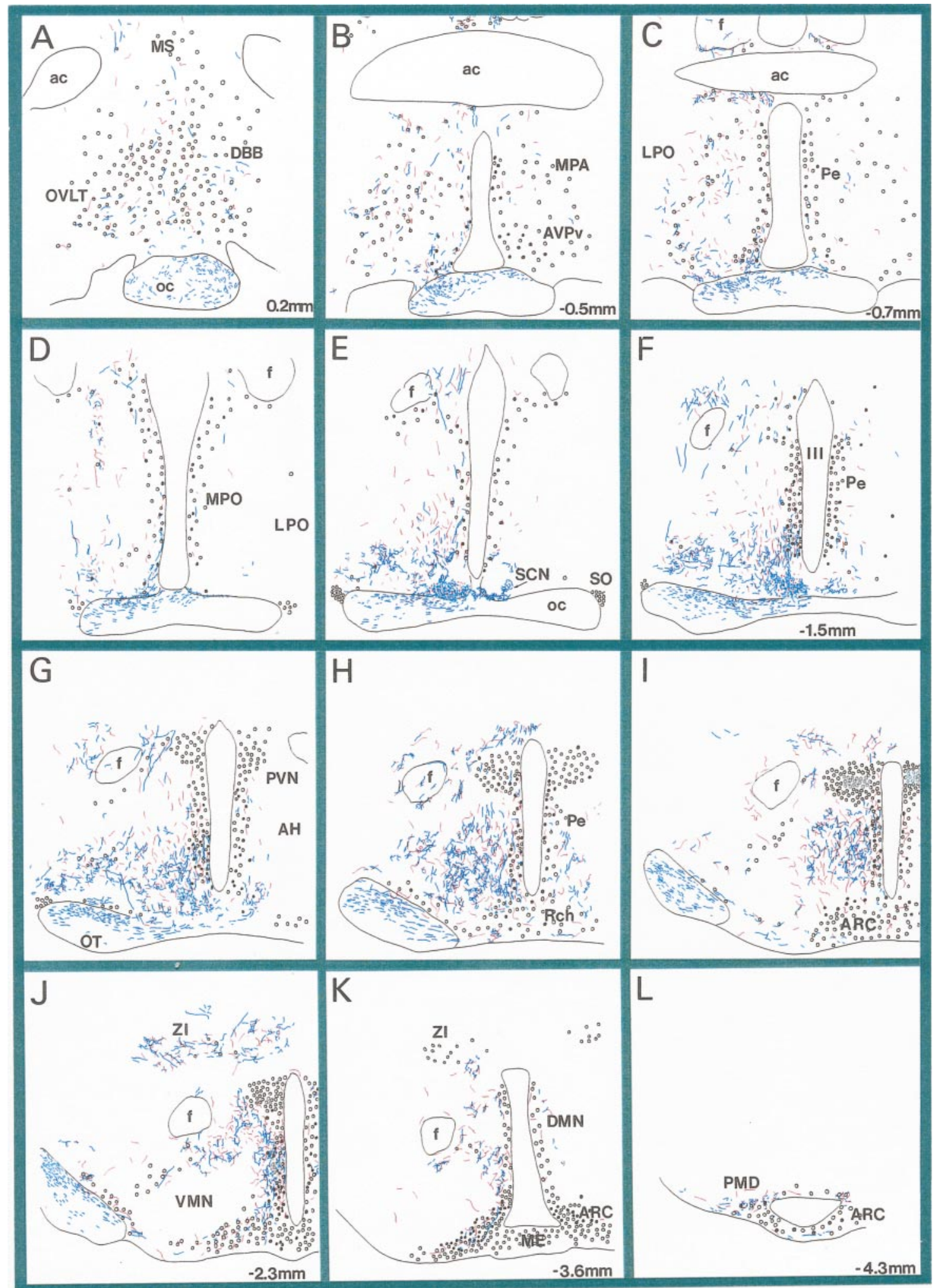

Figure 2. Distribution of LGN and SCN efferents in the hypothalamus. $A-L$, Camera lucida drawings of coronal, hypothalamic vibratome sections after immunostaining for PHA-L-filled LGN efferents (blue processes). Red processes represent PHA-L-labeled SCN efferents that were superimposed from matching vibratome sections of another experiment (Horvath, 1997). Circles represent neuroendocrine cells immunoreactive for fluorogold. Black filled circles are neuroendocrine cells that were TH-immunoreactive. Sections were taken between 0.2 and -4.3 mm in the anteroposterior axis, the number indicating the distance between the coronal level and bregma. $M S$, Medial septum; $O V L T$, organum vasculosum laminae terminalis; $D B B$, diagonal band of Broca; $o c$, optic chiasm; $a c$, anterior commissure; $M P A$, medial preoptic nucleus; $A V P v$, anteroventral periventricular nucleus; $L P O$, lateral preoptic area; $P e$, periventricular area; $M P O$, medial preoptic area; $S C N$, suprachiasmatic nucleus; $S O$, supraoptic nucleus; $I I I$, third ventricle; $f$, fornix; $P V N$, paraventricular nucleus; $A H$, anterior hypothalamus; $R c h$, retrochiasmatic area; $A R C$, arcuate nucleus; $V M N$, ventromedial nucleus; $Z I$, zona incerta; $D M N$, dorsomedial nucleus; $M E$, median eminence; $P M D$, dorsal premammillary nucleus; $O T$, optic tract. 

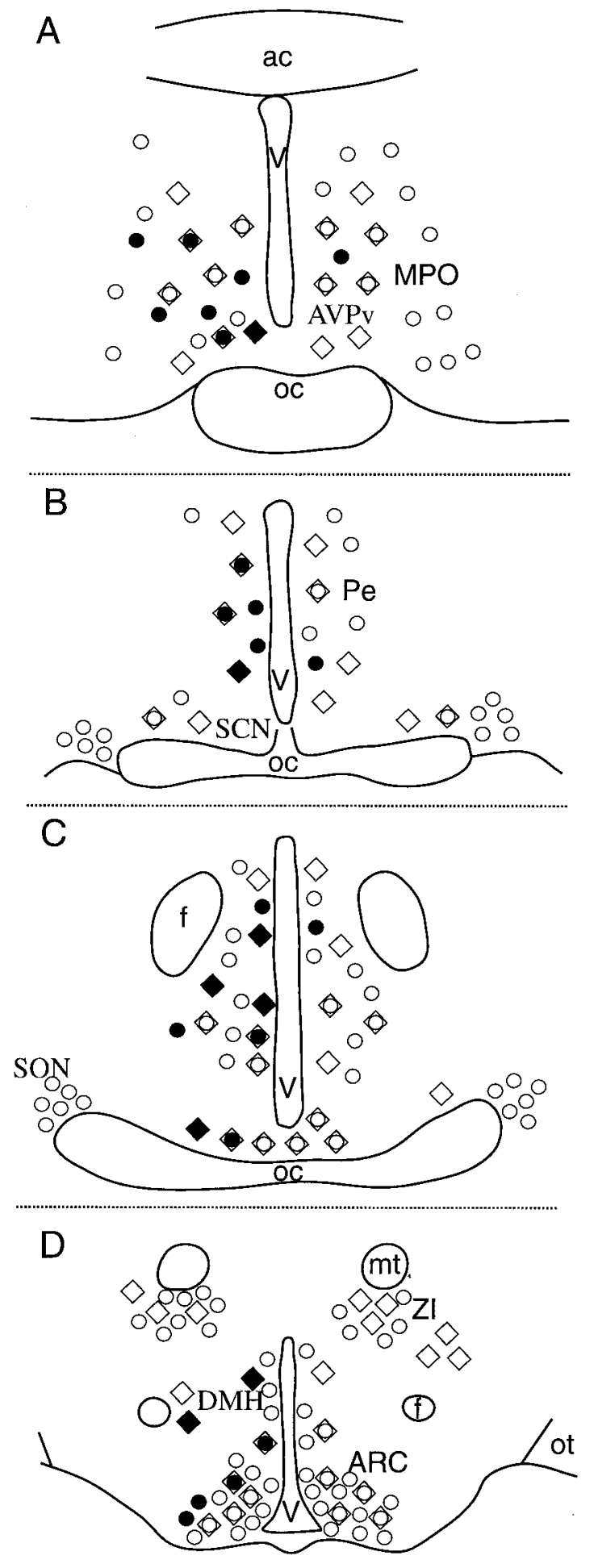

Figure 3. Distribution of dopamine-containing and/or neuroendocrine cells in the hypothalamus. Schematic illustrations of hypothalamic sections at the level of the medial preoptic area $(A V P v, M P O ; A)$, suprachiasmatic-periventricular areas $(P e ; B)$, retrochiasmatic-anterior hypothalamus area $(C)$, and arcuate nucleus $(A R C$; $D)$. Shown are the distribution patterns of TH-immunoreactive (diamonds) and fluorogoldlabeled (circles) cells, their colocalization (circles in diamonds), and those dopaminergic (filled diamonds) and/or neuroendocrine (filled circles) cells that were found to be targets of IGL efferents. $a c$, Anterior commissure; $o c$, optic chiasm; $P e$, periventricular area; $f$, fornix; $V$, third ventricle; $m t$, mammillothalamic tract; $Z I$, zona incerta; ot, optic tract; $S O$, supraoptic nucleus; $D M H$, dorsomedial hypothalamic nucleus. the AVPv, dark blue PHA-L boutons were found in contact with light brown $\mathrm{TH}$-immunoreactive cell bodies and proximal dendrites containing retrogradely transported dark blue FGimmunopositive granules (Figs. 3, $4 E-G 2$ ). Electron microscopic analysis revealed predominantly symmetrical synapses between PHA-L-immunoreactive boutons and neuroendocrine and/or dopamine-producing cell bodies and dendrites (Fig. 5).

\section{FG and enucleation experiments}

Animals that were binocularly enucleated and received FG injections into hypothalamic sites were perfused $5 \mathrm{~d}$ after the parallel interventions. This survival period was previously shown to be sufficient for the detection of anterogradely degenerated retinal axon terminals in the LGN (Takatsuji et al., 1991) and to allow FG to travel a distance of 5-6 $\mathrm{mm}$.

\section{FG labeling}

FG injection sites could be detected by fluorescence microscopy in discrete areas of the hypothalamus, including the anteroventral periventricular nucleus (Fig. 6A1) medial preoptic area (Fig. $6 B 1$ ), and an area above the suprachiasmatic nucleus (Fig. 6C1). For this experiment, only those animals in which the FG injection avoided the SCN were used.

Retrogradely labeled FG-immunoreactive perikarya and dendrites were observed throughout the hypothalamus. Although almost all regions contained retrogradely labeled cells, the highest number of FG-accumulating neurons were found in the medial preoptic area, periventricular areas, and the arcuate nucleus.

In the LGN, FG-immunoreactive perikarya were restricted to the IGL (Fig. 7). No retrogradely labeled neurons could be observed in either the vLGN or dLGN. Within the IGL, hypothalamo-projective neurons showed a homogeneous distribution (Fig. 7). Although retrogradely labeled cells were present predominantly in the IGL ipsilateral to the injection site, numerous labeled perikarya could also be detected in the contralateral IGL.

The immunoperoxidase labeling for FG was homogeneously distributed within the perikarya and dendrites of IGL neurons. Electron microscopic analysis revealed that all of the FGimmunoreactive perikarya of the IGL contained nuclei with numerous invaginations (Fig. $8 A$ ), whereas nearby neurons with round nuclei (not infolded) never contained immunoperoxidase. Although degenerated myelinated and unmyelinated axons and axon terminals were detected in the IGL, these fibers were never observed in close apposition to labeled or unlabeled cell bodies or proximal dendrites in the IGL. On the other hand, asymmetric synaptic contacts were frequently observed between degenerated retinal axon terminals and distal dendrites of both retrogradely labeled (Fig. 8B,C) and unlabeled IGL neurons.

\section{DISCUSSION}

LGN efferents innervated various hypothalamic sites. Although an abundant network of LGN fibers was detected in the SCN, a comparable innervation of the subparaventricular zone and other periventricular structures was also observed (Fig. 2). These results are in agreement with previous demonstrations of LGN efferents in various regions of the hypothalamus (Swanson et al., 1974; Ribak and Peters, 1975; Mikkelsen, 1990a,b; Moore et al., 1996). However, with the exception of a recent preliminary report (Moore et al., 1996), this study is the first to provide a detailed description of LGN efferents throughout the entire rat hypothalamus and to demonstrate an almost complete overlap between SCN and IGL projections in different hypothalamic nuclei. 

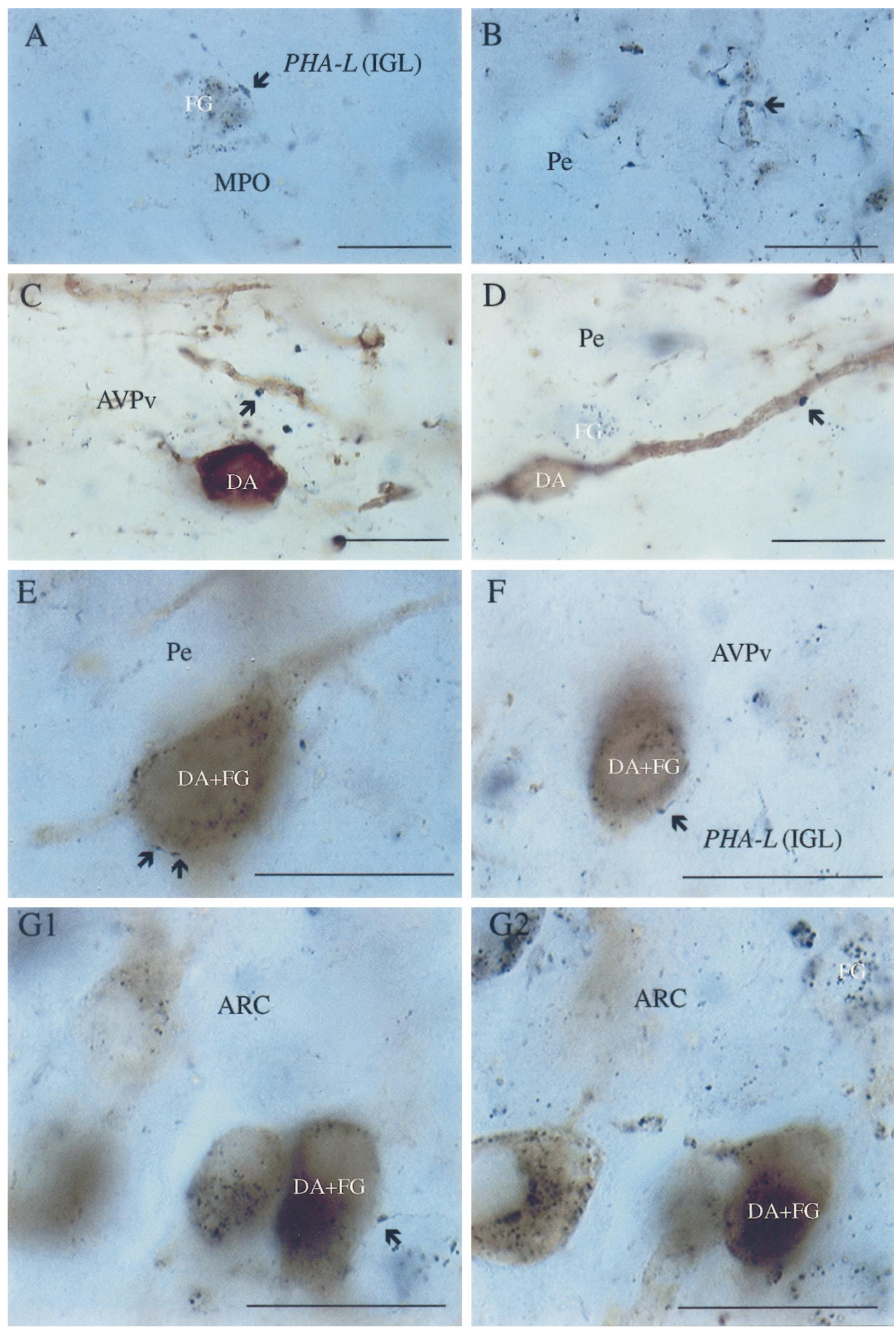

Figure 4. LGN efferents contacting hypothalamic neuroendocrine and/or dopamine cells. Light micrographs of a hypothalamic section after visualization for PHA-L-containing LGN efferents (dark blue boutons; arrows), retrogradely labeled, fluorogold-containing neuroendocrine cells (dark blue cytoplasmic inclusions), and TH (homogeneous brown cytoplasmic staining) in neuronal perikarya representing dopamine (DA)-producing cells. $A$, $B$, Dark blue boutons originating in the LGN in close proximity to an FG-containing perikaryon and dendritic process of the MPO and the periventricular area (Pe), respectively. $C$, $D$, Putative connections between IGL efferents (PHA-L-immunoreactive axon terminals; arrows) and non-neuroendocrine (FG-negative) dopamine cells in the anteroventral periventricular nucleus $(A V P v)$ and Pe. $E-G 1$, Retrogradely labeled (FG granules) dopamine cells (TH-immunoreactive) contacted by PHA-L-containing putative axon terminals (arrows) in the Pe $(E), \operatorname{AVPv}(F)$, and the lateral aspects of the arcuate nucleus $(A R C)(G 1)$. G2, Same cells as in $G 1$ but at a different focus plane to enhance the visibility of FG-immunoreactive cytoplasmic inclusions. Scale bars, $10 \mu \mathrm{m}$. 


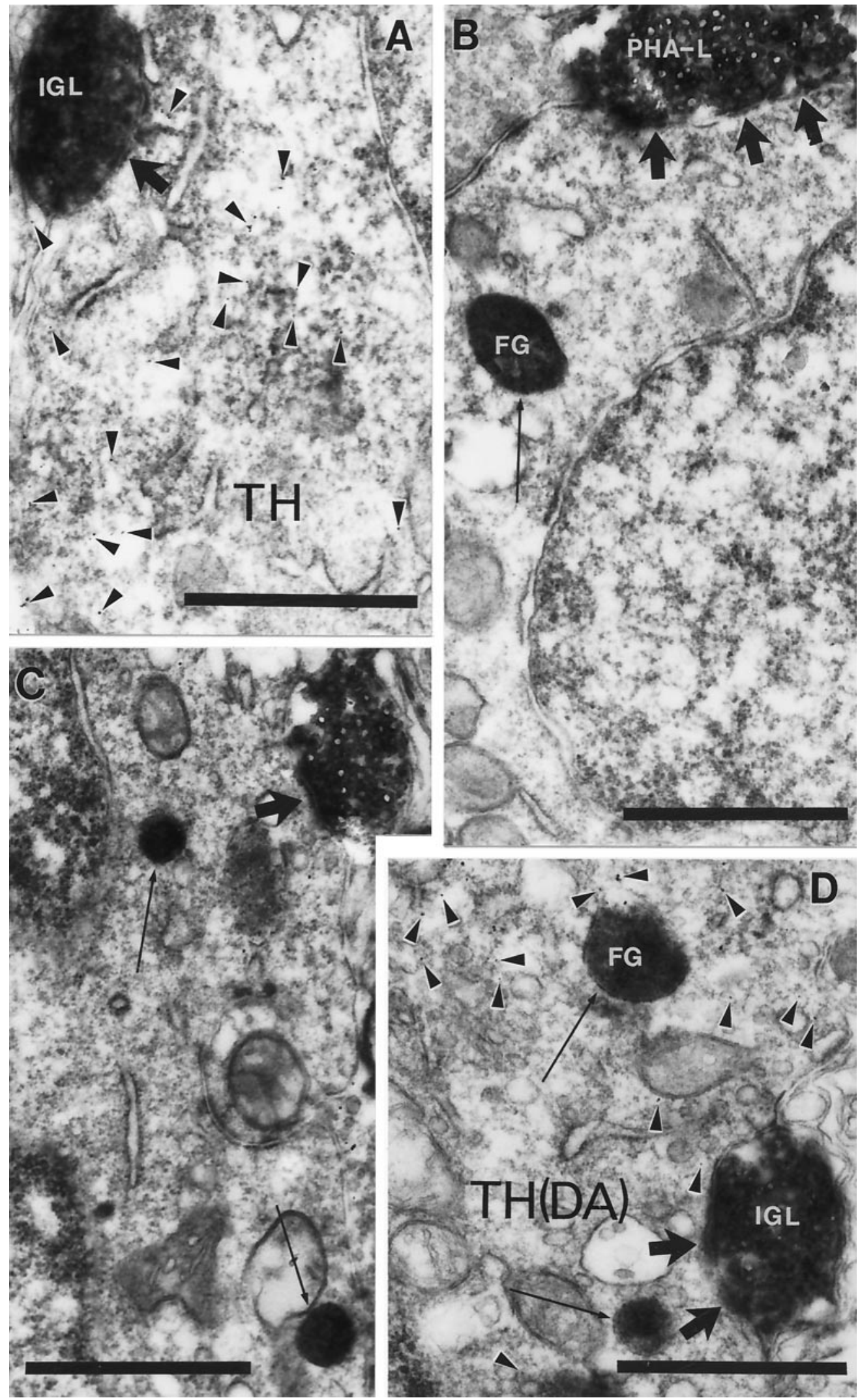

Figure 5. Synaptic interaction between IGL efferents and hypothalamic cells. Electron micrograph taken of the arcuate nucleus $(A)$, periventricular area $(B)$, MPO $(C)$, and anteroventral periventricular nucleus $(D)$ from the material triple immunolabeled for PHA-L, TH (arrowheads on $A, D$ point to immunogold), and FG (arrows). PHA-L-immunoreactive boutons originating in the IGL establish symmetric axosomatic $(A-C)$ and axodendritic (D) synaptic contacts (large arrows) with hypothalamic cells that contain $\mathrm{TH}$ and/or FG immunolabeling. Scale bars, $1 \mu \mathrm{m}$.
The exclusive appearance of retrogradely labeled cells in the IGL after hypothalamic FG injections is also in accordance with the result of Moore et al. (1996). In anterograde tracing experiments, they found that the IGL and not the vLGN contributes to the innervation of the hypothalamus. Our electron microscopic analysis revealed that the retrogradely labeled IGL perikarya contained exclusively infolded nuclei, and IGL projections established symmetric synaptic contacts with hypothalamic target cells. 

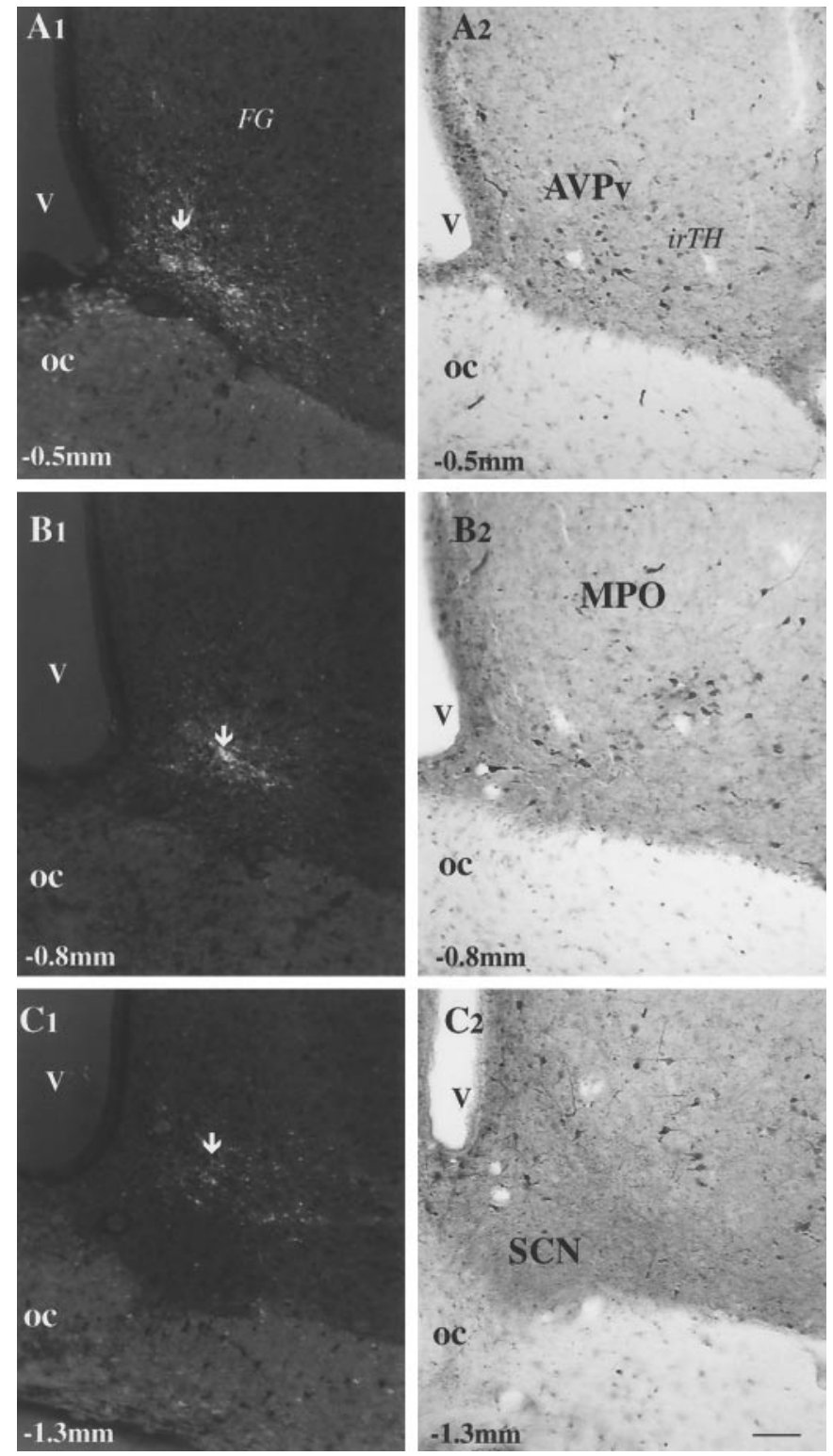

Figure 6. FG injection sites in the anterior hypothalamus and their relationships to local TH-immunoreactive cells. $A 1-C 2$, Micrographs taken from hypothalamic vibratome sections of animals that received FG injections in different anterior hypothalamic sites. $A 1, B 1, C 1, \mathrm{FG}$ injection sites (arrows) using ultraviolet light in the anteroventral periventricular nucleus $(A V P v)(A 1), \mathrm{MPO}(B 1)$, and an area above the SCN $(A 3)$ Only the labeled cells around the tip of the iontophoretic injection (arrows) have a high enough concentration of fluorogold to emit fluorescent light after immunostaining for FG. $A 2, B 2, C 2$, Light micrographs of the areas corresponding to the FG injections immunostained for $\mathrm{TH}$. TH-immunoreactive (irTH), putative dopaminergic cells are present in the areas where FG was injected (compare $A 1$ with $A 2, B 1$ with $B 2$, and $C 1$ with $C 2)$. Scale bar, $50 \mu \mathrm{m}$.

These characteristics are associated with inhibitory neurons (Ribak and Seress, 1983). Previous immunocytochemical studies demonstrated that IGL neurons produce enkephalin, neuropeptide Y, and GABA (Mantyh and Kemp, 1983; Takatsuji and Tohyama, 1989). It was also shown that IGL neurons and their projections to the SCN colocalize NPY and GABA (Moore and Speh, 1993; Moore and Card, 1994), and that these peptidergic terminals, in part, established symmetric synaptic contacts
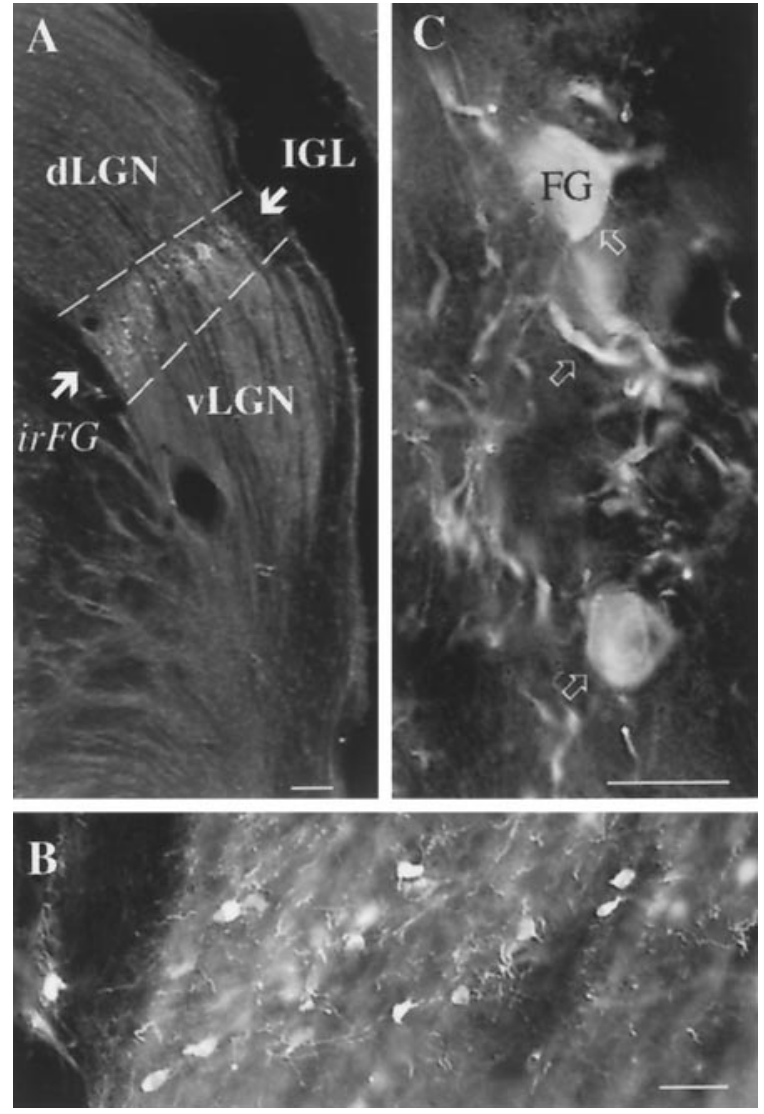

Figure 7. Distribution of retrogradely labeled IGL cells after hypothalamic FG injections. $A$, Light micrograph that demonstrates that retrogradely labeled, fluorogold-immunoreactive (irFG) LGN cells are restricted to the IGL and are not present in the dLGN or vLGN. $B, C$, High-power magnifications of FG-immunoreactive IGL cells. Arrows $C$ point to FG-immunoreactive cells and dendrites within the IGL. Scale bars: $A-C, 100,25$, and $10 \mu \mathrm{m}$, respectively.

(Moore et al., 1984). Thus, it is likely that the geniculohypothalamic tract innervating extrasuprachiasmatic sites may also be a GABAergic, NPY-containing pathway.

These experiments revealed that a population of LGN-targeted neurons in the hypothalamus are neuroendocrine cells; i.e., they have direct access to the portal vasculature of the median eminence or the organum vasculosum laminae terminalis. These cells, including those producing dopamine, were most frequently found in periventricular areas. The same hypothalamic cell populations were previously found to receive SCN input (Horvath, 1997), raising the possibility of convergent SCN and IGL inputs on the same hypothalamic perikarya. In light of the fact that the parent cells of the IGL efferents were found to receive direct visual input, it is reasonable to suggest that the integration of visual and circadian signals into the hypothalamo-pituitary axis may occur on the final output neurons of the hypothalamus (Fig. 9), adding another level of redundancy to the pathways via which the environment may regulate hormone secretions.

An increasing body of data indicate that visual signals may be conveyed to hypothalamic sites by pathways other than the SCN. In addition to direct retinal input to different hypothalamic sites (Hendrickson et al., 1972; Moore and Lenn, 1972; Pickard and Silverman, 1981; Riley et al., 1981; Johnson et al., 1988; Mikkelsen, 1992; Levine et al., 1994), the present and previous studies (Mikkelsen, 1990a,b; Moore et al., 1996) found that there 


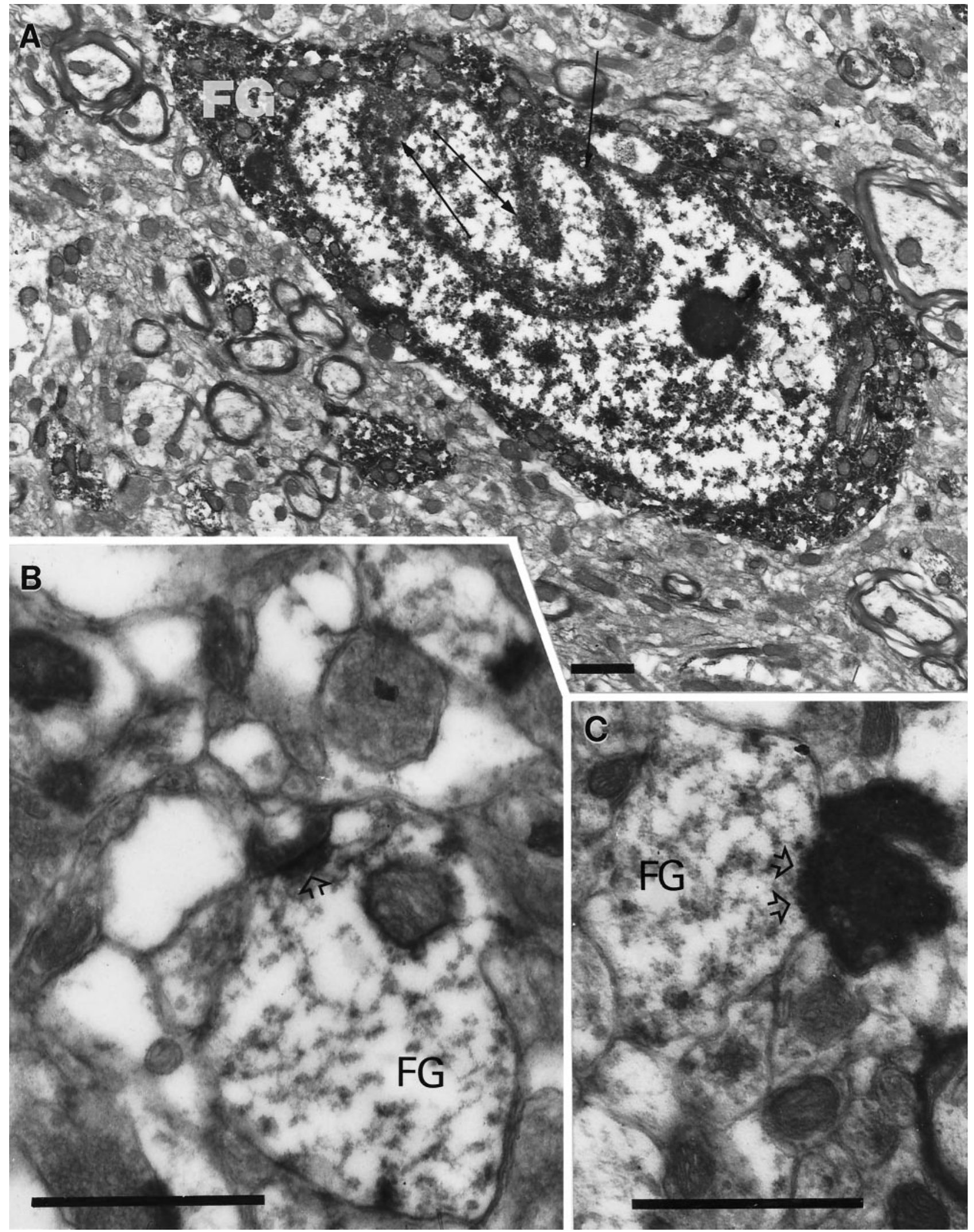

Figure 8. Electron microscopic analysis of the IGL after hypothalamic FG injection and binocular enucleation. $A$, Ultrastructural analysis of a hypothalamus-projective (FG) IGL cell demonstrates that the nucleus contains several infoldings (arrows), and the immunolabeling for FG is homogeneously distributed in the cytoplasm. $B, C$, Asymmetrical synapses (open arrowheads) between degenerated retinal fibers and distal dendrites of IGL neurons containing immunoperoxidase for FG. Scale bars, $1 \mu \mathrm{m}$. 


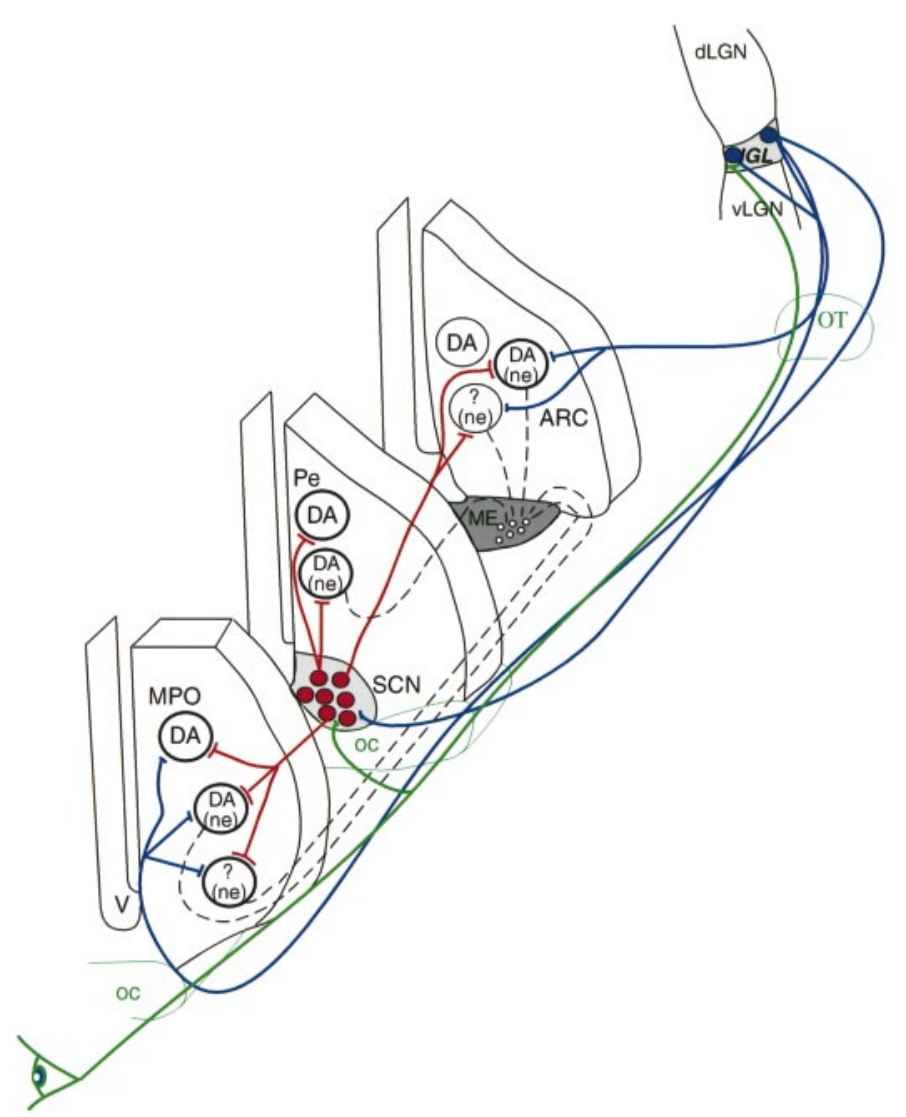

Figure 9. Schematic illustration of the relationship among visual, circadian, and neuroendocrine cells in the hypothalamus. Retinal efferents (green) innervate IGL neurons (filled blue circles) that project to the hypothalamus (blue lines) and innervate different populations of neurons. Subpopulations of these neurons in the MPO, periventricular area $(\mathrm{Pe})$, and arcuate nucleus $(A R C)$ contain dopamine $(D A)$ and/or are neuroendocrine (ne) revealed by systemic fluorogold labeling. A population of neurochemically unidentified (?) neuroendocrine cells were also found to receive IGL efferents. Neurons of the SCN (filled red circles) receive retinal (green) and IGL efferents (blue) and innervate (red lines) the same population of hypothalamic cells as IGL processes. $V$, Third ventricle; $o c$, optic chiasm; ot, optic tract. Dashed black lines indicate projections to fenestrated capillaries.

is an extensive projection of IGL neurons to hypothalamic sites, including the medial septum, diagonal band of Broca, bed nucleus of the stria terminalis, MPO, AVPv, periventricular areas, subparaventricular zone, dorsomedial nucleus, and a cell-sparse zone between the arcuate nucleus and the ventromedial hypothalamic nucleus. It was also demonstrated that retinorecipient IGL neurons innervated neuroendocrine cells, including those producing dopamine. These observations indicate that the participation of the IGL in the regulation of central mechanisms may not be restricted to the alteration of SCN activity, but the IGL may directly convey photic stimuli to neuroendocrine cells.

\section{Functional considerations}

Production and secretion of prolactin and $\mathrm{LH}$ from the anterior pituitary show diurnal patterns and are under the control of the mediobasal hypothalamus. Dopamine secreted into the portal capillaries is considered to be the major regulatory substance in prolactin production and release (Ben-Jonathan et al., 1977; BenJonathan, 1985). On the day of proestrus and every day in estrogen-primed, ovariectomized females, prolactin and LH secretions from the anterior pituitary increase in the afternoon
(Smith et al., 1976). This elevation of prolactin is, at least in part, attributable to decreased dopamine release (Neill et al., 1971). Significant decreases of median eminence dihidroxyphenilacetic acid and dehydroxyphenylalanine also occur in parallel with the increased prolactin secretion (Mai et al., 1994). Regarding LH secretion, it is suggested that the release from the inhibitory tone on LHRH neurons initiates both the afternoon (Kawakami et al., 1980) and preovulatory gonadotropin surges.

The SCN constitutes an essential component for normal control of $\mathrm{LH}$ and prolactin secretion in rodents. Destruction of the circadian clock blocks the preovulatory $\mathrm{LH}$ and prolactin surges and induces persistent estrus accompanied by hyperprolactinemia in intact female rats (Mai et al., 1994). A similar outcome occurs during constant light exposure, which first induces a delay (Watts and Fink, 1981a) but then abolishes the daily and preovulatory gonadotropin and prolactin surges (Critchlow, 1963; BrownGrant et al., 1973; Watts and Fink, 1981b). Interestingly, under these conditions, the circadian SCN activity will free run (Honma and Hiroshige, 1978). A plausible cause for altered hormone secretions could be that the rhythm of the free-running circadian pacemaker during constant light eventually will split into two running cycles (Pittendrigh and Daan; 1976; Morin and Cummings, 1982; Pickard and Turek; 1982; Swan and Turek, 1982, 1985). This, in turn, will impair most circadian rhythms and also underlies split daily surges of LH (Swan and Turek, 1982, 1985). Because these changes in circadian function were not described in rats, it is likely that during constant light exposure, there is a continuous signal from the eye to the final output neurons of the hypothalamus that maintains a subtle but steady activation of anterior pituitary cells producing $\mathrm{LH}$ and prolactin.

Our results elucidate a pathway through which these continuous signals can be conveyed from the eye to hypothalamic cells via the IGL. The observation that exposure to constant light induces the continuous expression of the early proto-oncogene c-fos in IGL cells but not in SCN neurons (Park et al., 1993; Edelstein and Amir, 1996) raises the possibility that the neuroendocrine cells described as receiving IGL (present study) and SCN (Horvath, 1997) inputs may be continuously altered by IGL rather than SCN signals. To elucidate the interaction of SCN and IGL signals further in the regulation of these hypothalamic cells exposed to constant light, the localization and possible segregation of these inputs on the same hypothalamic perikarya need to be determined.

Of particular interest regarding prolactin and $\mathrm{LH}$ secretions are those IGL-targeted dopamine cells that are located in the anteroventral periventricular nucleus. The critical role of this extrasuprachiasmatic area in the rhythmic regulation of anterior pituitary hormones has been recognized; similar to the effects of constant light exposure, it was found that selective destruction of this area abolishes ovarian cycles and results in the emergence of constant vaginal estrus (Wiegand and Terasawa, 1982). Therefore, it is likely that the IGL input to neuroendocrine and nonneuroendocrine dopamine cells of the AVPv may significantly contribute to the development of altered anterior pituitary hormone secretion induced by constant light exposure.

\section{Prolactin secretion}

Neuroendocrine dopamine cells of the AVPv and arcuate nucleus are known to send efferents to the median eminence region (van den Pol et al., 1984; Kawano and Daikoku, 1987) to participate in the suppression of prolactin secretion (Ben-Jonathan, 1985). Because the excitatory visual input on IGL neurons may be trans- 
lated to an increased inhibitory tone on the neuroendocrine dopamine cells (putative inhibitory projections from the IGL), the consequent decreased dopamine secretion can underlie a steady elevation of prolactin secretion during constant light.

\section{Gonadotropin secretion}

Dopamine interneurons of the AVPv were found to innervate GnRH cells (Horvath et al., 1993) and to receive IGL efferents (present study). Therefore, an increased inhibitory input (from the IGL) on these dopamine cells induced by constant light may affect the activity of GnRH neurons leading to a continuous, steady trigger for $\mathrm{LH}$ secretion.

In conclusion, this study provides evidence for a monosynaptic pathway between IGL neurons and hypothalamic cells outside of the SCN. It was demonstrated that IGL efferents innervate neuroendocrine cells, including those producing dopamine, and that their parent cells received direct retinal input. Therefore, it is suggested that a signaling modality exists between the eye and hypothalamic cells not involving the SCN that can regulate neuroendocrine and autonomic functions.

\section{REFERENCES}

Antunes-Rodriques J, McCann SM (1967) Effect of suprachiasmatic nucleus lesions on the regulation of luteinizing hormone secretion in the female rat. Endocrinology 81:666-670.

Ben-Jonathan N (1985) Dopamine: a prolactin-inhibiting hormone. Endocr Rev 6:564-589.

Ben-Jonathan N, Oliver C, Weiner HJ, Mical RS, Porter JC (1977) Dopamine in hypophysial portal plasma of the rat during the estrus cycle and throughout pregnancy. Endocrinology 100:452-458.

Brown-Grant K, Raisman G (1977) Abnormalities in reproductive function associated with destruction of the suprachiasmatic nuclei in female rats. Proc R Soc Lond B Biol Sci 198:279-296.

Brown-Grant K, Davidson JM, Greig F (1973) Induced ovulation in albino rats exposed to constant light. J Endocrinol 57:7-22.

Chan-Palay V, Zaborszky L, Köhler C, Goldstein M, Palay SL (1984) Distribution of tyrosine-hydroxylase immunoreactive neurons in the hypothalamus of rats. J Comp Neurol 227:467-494.

Critchlow V (1963) The role of light in neuroendocrine system. In: Advances in neuroendocrinology (Nalbanov AV, ed), pp 377-402. Urbana, IL: University of Illinois.

Edelstein K, Amir S (1996) Constant light induces persistent Fos expression in rat intergeniculate leaflet. Brain Res 731:221-225.

Hendrickson AE, Wagoner W, Cowan WM (1972) An autoradiographic and electron microscopic study of retinohypothalamic connections. Z Zellforsch 135:1-36.

Hickey TL, Spear PD (1976) Retinogeniculate projections in hooded and albino rats: an autoradiographic study. Exp Brain Res 24:523-529.

Honma KI, Hiroshige T (1978) Internal synchronization among several circadian rhythms in rats under constant light. Am J Physiol 235:244-249.

Horvath TL (1997) Suprachiasmatic efferents avoid phenestrated capillaries but innervate neuroendocrine cells including those producing dopamine. Endocrinology 138:1312-1320.

Horvath TL, Naftolin F, Leranth C (1992a) $\beta$-endorphin innervation of dopamine neurons in the rat hypothalamus; a light and electron microscopic double immunostaining study. Endocrinology 131:1547-1555.

Horvath TL, Naftolin F, Leranth C (1992b) GABAergic and catecholaminergic innervation of mediobasal hypothalamic $\beta$-endorphin cells projecting to the medial preoptic area. Neuroscience 51:391-399.

Horvath TL, Naftolin F, Leranth C (1993) Luteinizing hormonereleasing hormone and gamma aminobutiric acid neurons in the medial preoptic area are synaptic targets of dopamine axons originating in anterior periventricular areas. J Neuroendocrinol 5:71-79.

Johnson RF, Morin LP, Moore RY (1988) Retinohypothalamic projections in the hamster and rat demonstrated using cholera toxin. Brain Res 462:301-312.

Jonsson G, Fuxe K, Hokfelt T (1971) On the catecholamine innervation of the hypothalamus, with special reference to the median eminence. Brain Res 40:271-281.

Kawakami M, Arita J, Yoshioka E (1980) Loss of oestrogen-induced daily surges of prolactin and gonadotrophins by suprachiasmatic nucleus lesions in ovariectomized rats. Endocrinology 106:1087-1092.

Kawano H, Daikoku S (1987) Functional topography of the rat hypothalamic dopamine neuron systems: retrograde tracing and immunocytochemical study. J Comp Neurol 265:242-253.

Levine JD, Zhao X-S, Miselis RR (1994) Direct and indirect retinohypothalamic projections to the supraoptic nucleus in the female albino rat. J Comp Neurol 341:214-224.

Mai LM, Shieh KR, Pan JT (1994) Circadian changes of serum prolactin levels and tuberoinfundibular dopaminergic neuron activities in ovariectomized rats treated with or without estrogen: the role of the suprachiasmatic nucleus. Neuroendocrinology 60:520-526.

Mantyh PW, Kemp JA (1983) The distribution of putative neurotransmitters in the lateral geniculate nucleus of the rat. Brain Res 288:344-348.

Merchenthaler I (1991) Neurons with access to the general circulation in the central nervous system of the rat: a retrograde tracing study with fluoro-gold. Neuroscience 44:655-662.

Mikkelsen JD (1990a) A neuronal projection from the lateral geniculate nucleus to the lateral hypothalamus of the rat demonstrated with Phaseolus vulgaris leucoagglutinin tracing. Neurosc Lett 116:58-63.

Mikkelsen JD (1990b) Projections from the lateral geniculate nucleus to the hypothalamus of the Mongolian gerbil (Meriones unguiculatus): an anterograde tracing study. J Comp Neurol 299:493-508.

Mikkelsen JD (1992) Visualization of efferent retinal projections by immunocytochemical identification of cholera toxin subunit B. Brain Res Bull 28:619-623.

Moore RY, Lenn NJ (1972) A retinohypothalamic projection in the rat. J Comp Neurol 146:1-14.

Moore RY, Speh JC (1993) GABA is the principal neurotransmitter of the circadian system. Neurosci Lett 150:112-116.

Moore RY, Card JP (1994) Intergeniculate leaflet: an anatomically and functionally distinct subdivision of the lateral geniculate comples. J Comp Neurol 344:403-430.

Moore RY, Gustafson EL, Card JP (1984) Identical immunoreactivity of afferents to the rat suprachiasmatic nucleus with antisera against avian pancreatic polypeptide, molluscan cardioexcitatory peptide and neuropeptide Y. Cell Tissue Res 236:41-46.

Moore RY, Moga MM, Weis R (1996) Intergeniculate leaflet (IGL) and ventral lateral geniculate (VLG) projections in the rat. Presented at the 26th Annual Meeting of the Society for Neuroscience: Washington, DC, Abstract 65.8.

Morimoto Y, Oishi T, Arisue K, Ogawa Z, Tanaka F (1975) Circadian rhythm of plasma corticosteroid in adult female rats: chronological shifts in abnormal lighting regimens and connection with oestrus cycle. Acta Endocrinol (Copenh) 80:527-541.

Morin LP, Cummings LA (1982) Splitting of wheelrunning rhythms by castrated or steroid treated male and female hamsters. Physiol Behav 29:665-675.

Morin LP, Blanchard J (1993) Organization of the hamster paraventricular hypothalamic nucleus. J Comp Neurol 332:341-357.

Neill JD, Freeman ME, Tilson SA (1971) Control of the proestrus surge of prolactin and luteinizing hormone secretion by estrogen in the rat. Endocrinology 89:1448-1453.

Nir I, Hirschmann N (1982) Effect of constant light and darkness on pituitary and serum gonadotropin and sex hormone levels of parturient rats. J Neural Transm 55:157-168.

Pan JT, Gala RR (1985) Central nervous system regions involved in the estrogen-induced afternoon prolactin surge. I. Lesion studies. Endocrinology 117:382-387.

Park HT, Beak SY, Kim BS, Kim JB, Kim JJ (1993) Profile of Fos-like immunoreactivity induction by light stimuli in the intergeniculate leaflet is different from that of the suprachiasmatic nucleus. Brain Res 610:334-339.

Paxinos G, Watson C (1986) The rat brain in stereotaxic coordinates. Orlanado: Academic.

Pickard GE, Silverman JA (1981) Direct retinal projections to the hypothalamus piriform cortex, and accessory optic nuclei in the golden hamsters as demonstrated by a sensitive anterograde horseradish peroxidase technique. J Comp Neurol 196:155-172.

Pickard GE, Turek FW (1982) Splitting of the circadian rhythm of activity is abolished by unilateral lesions of the suprachiasmatic nuclei. Science 215:1119-1121.

Pieper DR, Gala RR (1979) The effect of light on the prolactin surges of pseudopregnant and ovariectomized rats. Biol Reprod 20:7727-732. 
Pittendrigh CS, Daan S (1976) A functional analysis of the circadian pacemakers in nocturnal rodents. V. Pacemakers structure: a clock for all season. J Comp Physiol 106:333-355.

Ribak CE, Peters A (1975) An autoradiographic study of projections from the lateral geniculate body of the rat. Brain Res 92:341-368.

Ribak CE, Seress L (1983) Five types of basket cells in the hippocampal dentate gyrus: a combined Golgi and electron microscopic study. J Comp Neurol 12:577-597.

Riley JN, Card JP, Moore RY (1981) A retinal projection to the lateral hypothalamus in the rat. Cell Tissue Res 214:257-269.

Sartin JL, Bruot BC, Orts RJ (1981) Changes in serum prolactin following blinding and constant light exposure. J Endocrinol Invest 4:97-108.

Smith MS, Freeman ME, Neill JD (1976) The control of progesterone secretion during the estrous cycle and early pseudopregnancy in the rat: prolactin, gonadotropin and steroid levels associated with rescue of the corpus luteum of pseudopregnancy. Endocrinology 96:219-226.

Sterner MR, Cohen IR (1995) Steroid treatment fails to induce an afternoon luteinizing hormone or prolactin surge in rats exposed to short-term constant light at the time of ovariectomy. Neuroendocrinology 62:231-237.

Swann J, Turek FW (1982) Cycle of lordosis behavior in female hamsters whose circadian activity rhythm has split into two components. Am J Physiol 243:112-118.

Swann JM, Turek FW (1985) Multiple circadian oscillators regulate the timing of behavioral and endocrine rhythms in female golden hamsters. Science 228:898-900.

Swanson LW, Cowan WM, Jones EG (1974) An autoradiographic study of the efferent projections of the ventral lateral geniculate nucleus in the albino rat and cat. J Comp Neurol 156:143-164.

Takatsuji K, Tohyama M (1989) The organization of the rat lateral geniculate body by immunocytochemical analysis of neuroactive substances. Brain Res 480:198-209.
Takatsuji K, Miguel-Hialgo J-V, Tohyama M (1991) Retinal fibers make synaptic contact with neuropeptide $\mathrm{Y}$ and enkephalin immunoreactive neurons in the intergeniculate leaflet of the rat. Neurosci Lett 125:73-76.

van der Beek EM, Horvath TL, Wiegant VM, van der Hurk R, Buijs RM (1997) Evidence for a direct neuronal pathway from the suprachiasmatic nucleus to the gonadotropin-releasing hormone system: combined tracing and light- and electron-microscopical immunocytochemical studies. J Comp Neurol 384:569-579.

van den Pol A, Herbst R, Powel J (1984) Tyrosine hydroxylase immunoreactive neurons of the hypothalamus. A light and electron microscopic study. Neuroscience 13:1117-1156.

Vaticon MD, Fernandez-Galaz C, Esquifino A, Tejero A, Aguilar E (1980) Effects of constant light on prolactin secretion in adult female rats. Horm Res 12:277-288.

Watts AG, Fink G (1981a) Effects of short-term constant light on the proestrous luteinizing hormone surge and pituitary responsiveness in the female rat. Neuroendocrinology 33:176-180.

Watts AG, Fink G (1981b) Constant light blocks diurnal but not pulsatile release of luteinizing hormone in the ovariectomized rat. J Endocrinol 89:141-146.

Watts AG, Swanson LW (1987) Efferet projections of the suprachiasmatic nucleus: II. Studies using retrograde transport of fluorescent dyes and simultaneous peptide immunohistochemistry in the rat. J Comp Neurol 258:230-252.

Watts AG, Swanson LW, Sanchez-Wattz G (1987) Efferent projections of the suprachiasmatic nucleus: I. Studies using anterograde transport of Phaseolus vulgaris leucoagglutinin in the rat. J Comp Neurol 258:204-229.

Wiegand SJ, Terasawa E (1982) Discrete lesions reveal functional heterogeneity of suprachiasmatic structures in regulation of gonadotrophin secretion in the female rat. Neuroendocrinology 34:395-404. 